\title{
O TEMA TRANSVERSAL ORIENTAÇÃO SEXUAL NOS PCN E A ATITUDE DOS PROFESSORES: CONVERGENTES OU DIVERGENTES?
}

\section{THE TRANSVERSAL THEME SEXUAL ORIENTATION IN THE NCP AND TEACHERS ATTITUDE: CONVERGENT OR DIVERGENT?}

\author{
Andreia Lira ${ }^{1}$, Zélia Jofili ${ }^{2}$ \\ ${ }^{1}$ Universidade Federal Rural de Pernambuco, liraeduca@gmail.com \\ ${ }^{2}$ Universidade Federal Rural de Pernambuco, jofili@gmail.com
}

\section{RESUMO}

Os Parâmetros Curriculares Nacionais (PCN) estabelecem a orientação sexual como um dos temas transversais e, por sua complexidade, contempla as mais diversas áreas de conhecimento, mas comumente é associada aos conteúdos dos sistemas reprodutores abordados em Ciências e Biologia nos ensinos fundamental e médio, respectivamente. Nesse sentido, buscou-se conhecer a atitude de professores de Ciências Biológicas nas aulas de orientação sexual. Foram criadas cinco características dentre algumas daquelas que os PCN apontam como necessárias para o desenvolvimento do tema: "clareza", "sistematização", "atitudes de acolhimento às expressões dos estudantes", "domínio de conteúdo" e "aspectos trans-disciplinares". Convergências e divergências foram identificadas entre a prática dos professores e os aspectos dos PCN escolhidos para o estudo como categorias de análise. Ficaram identificadas convergências nas categorias "sistematização" e "atitudes de acolhimento", e divergências em "aspectos transdisciplinares". No entanto, não foram identificadas divergências nem convergências explicitas nas categorias "clareza" e "domínio de conteúdo".

Palavras-chave: Temas transversais, Orientação sexual, PCN, Ensino de Ciências.

\begin{abstract}
The National Curricular Parameters (PCN) establish sexual orientation as one of the transversal subjects and, because of its complexity, contemplates the most diverse areas of knowledge, but it is commonly associated with the contents of the reproductive systems approached in Sciences and Biology, in basic education and high school, respectively. In this direction, knowing the attitude of teachers of Biological Sciences in sexual orientation classes was searched. Five characteristics were created among some of the ones recomended by The PCN, as necessary to the development of the theme: "clarity", "systematization", "attitudes acceptance to the students expressions", "content domain", and "transdisciplinar aspects". Convergences and divergences were identified between teachers' practices and The PCN aspects chosen as categories of analysis to the study. Convergences were identified in "systematization" and "attitudes of acceptance", and divergences in "transdisciplinar aspects". However, neither explicit divergences nor convergences were identified in "clarity" and "content domain".
\end{abstract}

Keywords: sexual orientation, transversal subjects, NCP, Sciences.

\section{INTRODUÇÃO}


Os Parâmetros Curriculares Nacionais (PCN) buscam intensificar, entre os educadores do nosso país, a discussão da prática e do posicionamento frente às questões educacionais, econômicas, políticas e sociais. Seus organizadores destacam, dentre as razões fundamentais desse trabalho, a contribuição, para que profundas e imprescindíveis transformações, há muito desejadas, se façam no panorama educacional brasileiro e o posicionamento do professor, como principal agente desta tarefa.

Segundo os PCN é a partir da década de 1980 que o número de trabalhos na área da sexualidade nas escolas aumentou em virtude da preocupação dos educadores com o grande crescimento da gravidez indesejada entre adolescentes e do risco da infecção pelo HIV (vírus da Aids) (BRASIL, 1999).

São notórias, as limitações da abordagem sobre a reprodução humana, realizada pelas escolas, pois esse trabalho não contempla as ansiedades e curiosidades entre as crianças e adolescentes. É nesta perspectiva que os PCN de orientação sexual tentam através de sua proposta, redimensionar a prática pedagógica para que alcance o todo da sexualidade, legitimando e também delimitando o papel do educador, para que, não se restrinja às informações físico-anatômicas, que remetem apenas a um cunho informativo e não trazem resultados significativos. É necessário viabilizar um processo de atuação do professor em que o mesmo abranja o tema em sua complexidade, contribuindo desse modo com a aprendizagem.

Praticamente todas as escolas trabalham o aparelho reprodutivo em Ciências Naturais. Geralmente o fazem por meio da discussão sobre a reprodução humana, com informações ou noções relativas à anatomia e fisiologia do corpo humano. Essa abordagem normalmente não abarca as ansiedades e curiosidades das crianças, nem o interesse dos adolescentes, pois enfoca apenas o corpo biológico e não inclui a dimensão da sexualidade. Sabe-se que as curiosidades das crianças a respeito da sexualidade são questões muito significativas para a subjetividade, na medida em que se relacionam com o conhecimento das origens de cada um e com o desejo de saber. A satisfação dessas curiosidades contribui para que o desejo de saber seja impulsionado ao longo da vida, enquanto a não-satisfação gera ansiedade, tensão e, eventualmente, inibição da capacidade investigativa. A oferta, por parte da escola, de um espaço em que as crianças possam esclarecer suas dúvidas e continuar formulando novas questões, contribui para o alívio das ansiedades que muitas vezes interferem no aprendizado dos conteúdos escolares (BRASIL, 1999, p. 292).

Para que os objetivos dos PCN sejam alcançados pelos mediadores da orientação sexual, o documento apresenta algumas características necessárias para o profissional que realizará o trabalho. São elas: clareza, amplitude, flexibilidade, sistematização, 
prática dialógica, prática reflexiva, transversalidade, disponibilidade e abertura para o trabalho, atitudes de acolhimento às expressões dos educandos, disponibilidade para ouvir e responder, preparo dos educadores. (BRASIL, 1999).

Esse direcionamento formou a base para a montagem de uma síntese das características apontadas acima. Foram selecionadas as seguintes características: clareza, sistematização, atitudes de acolhimento às expressões dos estudantes, domínio de conteúdo e aspectos transdisciplinares, que deram início à proposta investigativa como nossas categorias de análise, que explicitaremos no desenvolvimento.

Partindo do pressuposto de que a orientação sexual nas escolas, não está tendo resultados eficazes, buscamos nesta pesquisa, responder a seguinte questão:

As atitudes dos professores nas aulas de orientação sexual contemplam as características recomendadas pelos PCN?

Por isso estabelecemos como objetivo investigar se a postura dos professores na abordagem da orientação sexual na escola contempla as seguintes características: clareza; sistematização; atitudes de acolhimento às expressões dos estudantes; domínio do conteúdo a ser ensinado; e aspectos da transdisciplinaridade; selecionadas dentre algumas recomendadas pelos PCN.

Dentre algumas das opções apontadas pelos PCN para a Orientação Sexual, está a de integrá-la através da transversalidade, de forma que tanto a concepção quanto os objetivos e conteúdos propostos encontrem-se contemplados nas diversas áreas do conhecimento.

Assim, o trabalho de orientação sexual também implica o tratamento de questões que nem sempre estarão articuladas com as áreas do currículo, emergindo e exigindo do professor flexibilidade, disponibilidade e abertura para trabalhá-las. Algumas pesquisas, porém, vêm questionando as condições do professor de exercer este papel no dia-a-dia na escola.

À escola tem sido atribuída a responsabilidade de preencher algumas lacunas, cabendo aos professores das diversas áreas do conhecimento a tarefa de orientação quanto à sexualidade, numa perspectiva transdisciplinar. O estudo desenvolvido por Oliveira (2001) mostra que os professores apresentam uma resistência para assumirem, na prática pedagógica, um trabalho sistemático, que envolva os vários aspectos da 
sexualidade, procurando eximir-se dessa tarefa, deixando-a a cargo dos professores de Ciências e/ou Biologia. Serão esses resultados consequência de como representam a sexualidade?

Os docentes representam a sexualidade como um fator fundamental sobre o qual os alunos necessitam ser esclarecidos, o que vem demonstrar uma preocupação com problemas sociais, tais como: gravidez precoce, o aborto e a Aids. Mas os docentes se contradizem, apesar de mostrarem-se receptivos à discussão da temática da sexualidade, ela encontra-se associada aos valores, aos tabus e aos preconceitos deles. (OLIVEIRA, 2001, p.134).

Não obstante, Os PCN apontam algumas sugestões de trabalho nas mais diferentes áreas de conhecimento. Apontam, ainda, inúmeras outras sugestões para trabalhar a temática em três blocos de conteúdos, respectivamente: corpo-matriz da sexualidade; relações de gênero e prevenção das doenças sexualmente transmissíveis/Aids, nas mais diversas áreas: geografia, arte, matemática, educação física, língua estrangeira e ciências naturais.

Parece-nos relevante diante do que foi estabelecido pelos PCN, para a abordagem do tema, considerar que o próprio documento dá margem para compreendermos que a abrangência dos temas relacionados à sexualidade inviabiliza sua proposta transversal, e segundo essa afirmativa, contraditoriamente discorrem sobre a possibilidade de termos uma disciplina para o tema, pois se referem a um espaço próprio para as discussões, com a participação ativa dos educandos:

[...] a sexualidade se impõe, na sociedade contemporânea, como um dos maiores interesses dos adolescentes, exigindo posicionamentos e atitudes cotidianas. Temáticas como a gravidez na adolescência, masturbação, homossexualidade, iniciação sexual, pornografia e erotismo, aborto, violência sexual e outras, são exemplos de questões que extrapolam a possibilidade da transversalização pelas disciplinas e demandam espaço próprio para serem refletidas e discutidas. São temas polêmicos, que envolvem questões complexas e demandam tempo para serem aprofundadas, com ampla participação dos alunos, além de exigirem maior preparo do educador (BRASIL, 1999, p. 331).

Não são poucos os profissionais que se sentem inseguros em abordar a temática, por não apresentarem as características acima apontadas. Alguns insistem que a orientação sexual deve ser de responsabilidade apenas do professor de Ciências e de Biologia.

$\mathrm{Na}$ proposta dos $\mathrm{PCN}$, o profissional responsável pela orientação sexual, não é necessariamente um professor de Ciências, mas o pré-requisito está em ter as características indispensáveis à abordagem: 
O profissional que se responsabiliza por esse trabalho pode ser um professor de qualquer matéria ou educador com outra função na escola (orientador educacional, coordenador pedagógico ou psicólogo, por exemplo). O importante é que seja alguém que tenha bom contato com os alunos e, portanto, um interlocutor confiável e significativo para acolher as expectativas, opiniões e dúvidas, além de ser capaz de conduzir debates sem impor suas opiniões. Não constitui pré-requisito que o professor seja da área de ciências (comumente associada à sexualidade), já que não se trata de abordagem predominantemente biológica da sexualidade. Importa é que tenha interesse e disponibilidade para esse trabalho, assim como flexibilidade e disposição pessoal para conhecer e questionar seus próprios valores, respeitando a diversidade dos valores atribuídos à sexualidade na sociedade atual (BRASIL, 1999, p.332).

Contraditoriamente ao que estipula sobre a transversalidade na abordagem da orientação sexual, os próprios PCN, em determinado momento, parecem caracterizar a abordagem da temática como sendo de conhecimento especializado:

É necessário que o educador tenha acesso à formação específica para tratar de sexualidade com crianças e jovens na escola, possibilitando a construção de uma postura profissional e consciente no trato desse tema. Os professores necessitam entrar em contato com suas próprias dificuldades diante do tema, com questões teóricas, leituras e discussões referentes à sexualidade e suas diferentes abordagens; preparar-se para a intervenção prática junto aos alunos e ter acesso a um espaço grupal de produção de conhecimento a partir dessa prática, se possível contando com assessoria especializada. A formação deve ocorrer de forma continuada e sistemática [...] (BRASIL, 1999, p. 303).

\section{DESENVOLVIMENTO}

Classificamos este estudo como descritivo, apoiados em Oliveira (2005) que define este viés da pesquisa qualitativa como sendo:

Abrangente, permitindo uma análise do problema de pesquisa em relação aos aspectos sociais, econômicos, políticos, percepções de diferentes grupos, comunidades, entre outros aspectos. Também é utilizada para a compreensão de diferentes comportamentos [...] (OLIVEIRA, 2005, p.74).

Nossos participantes foram seis professores da rede Estadual de ensino da Região Metropolitana do Recife, que lecionam em três escolas distintas.

A escolha dos mesmos teve como critérios:

- a) estarem dispostos a ser entrevistados e lecionarem no mesmo município, facilitando a disponibilidade para as entrevistas;

- b) Terem sua formação em Ciências Biológicas e atuarem como professores no ensino de Ciência e/ou Biologia, pois habitualmente os mesmos são incumbidos da orientação sexual na escola, por terem no currículo algumas temáticas 
comumente relacionadas, como é o caso dos sistemas reprodutores feminino e masculino, abordagem sobre os microorganismos causadores de doenças sexualmente transmissíveis, etc.

O levantamento dos dados foi feito por meio de entrevistas semi-estruturadas, para os participantes com roteiros pré-estabelecidos para os docentes, na aplicação dos questionamentos, contudo, surgiram perguntas que não constavam do roteiro, pois variavam de acordo com a interação dos mesmos.

Aplicamos um piloto da entrevista, visando testar o vocabulário empregado nas questões, além de assegurar que as questões feitas possibilitariam a coleta dos dados que se pretendia investigar.

Os professores participantes foram informados sobre a finalidade, procedimentos e ética da pesquisa. Aqueles que concordaram com o estudo, responderam ao Termo de Consentimento Livre e Esclarecido, autorizando a utilização dos dados.

Foram realizadas entrevistas semi-estruturadas, individualmente, sendo as perguntas e respostas gravadas em aparelho MP4. As entrevistas foram realizadas nas próprias escolas, dos sujeitos envolvidos na pesquisa, de acordo com a disponibilidade de dia e horário de cada um deles. O tempo de entrevista variou entre vinte e noventa minutos. As entrevistas foram transcritas, para análise.

A partir da análise das transcrições surgiu a necessidade do desdobramento das categorias e foram criadas subcategorias identificando as que foram mais e menos frequentemente mencionadas, em ordem decrescente da frequência em que apareciam, as mais pontuadas foram chamadas de prevalentes, sendo estas as nossas categorias de análise, conforme descrito adiante.

\section{CLAREZA}

Para esta categoria evidenciamos sete subcategorias, dentre as quais, a correção da linguagem foi a mais citada. Os professores apontaram que faziam a correção da linguagem em suas abordagens. Essa subcategoria foi alvo de nossa análise, interpretação e discussão. As outras estão apenas mencionadas algumas das falas que caracterizam essas subcategorias, com exceção da subcategoria (d) ajuda de outros 
profissionais, para a qual realizamos uma sucinta discussão.

\begin{tabular}{|l|l|l|l|l|l|}
\hline \multicolumn{2}{|c|}{ Subcategorias } & \multicolumn{3}{c|}{$\begin{array}{c}\text { Distribuição das respostas dos } \\
\text { professores }\end{array}$} \\
\hline a. Correção da linguagem & P1 & P2 & P3 & & \\
\hline b. Transposição didática & P1 & & & P5 & \\
\hline c. Contextualização do conteúdo & P1 & & P3 & & \\
\hline d. Ajuda de outros profissionais & & P2 & P3 & & \\
\hline e. Abrangência da temática impossibilita a clareza da abordagem & & P2 & & & P6 \\
\hline f. Não sabe a resposta, porém dispõe-se a pesquisar & & P2 & & & \\
\hline g. Questões sobre higienização & & & P3 & & \\
\hline
\end{tabular}

Quadro 1 - Respostas dos professores em relação às subcategorias da categoria clareza.

a. Correção da linguagem: O vocabulário dos adolescentes via de regra é bem distinto, permeado por gírias e algumas vezes até palavras de baixo calão, neste caso notamos a preocupação dos professores em corrigir, com o objetivo de informar os termos corretos (científicos). Isto foi observado na fala de P1, P2 e P3.

Eu transformo tudo em uma linguagem mais cientifica, digo que não é assim, o caminho não é este, a gente está estudando e precisa ter um bom vocabulário, às vezes as palavras são mais preconceituosas, é por aí que eu falo (P2).

Observamos, nos participantes, a preocupação de ensinar aos estudantes, palavras com uma conotação científica, através da correção da linguagem, que os educandos expressam e que frequentemente não corresponde aos conceitos corretos e precisa ser corrigida. Diante disso nos respaldamos nos PCN que explicitam a necessidade de que a linguagem na abordagem da orientação sexual seja clara, através da simplicidade e objetividade. Ressaltam que os meios de comunicação diversos, contribuem para a produção de conceitos e explicações errôneas e até fantasiosas, pois as suas manifestações têm assumido relevante papel na sociedade, principalmente entre os adolescentes, estimulando a moldar comportamentos, informando e veiculando campanhas educativas, que nem sempre são dirigidas e adequadas aos adolescentes. Através da moralização e reforço aos preconceitos, o documento enfatiza que informações corretas do ponto de vista científico ou esclarecimentos sobre as questões trazidas pelos educandos são fundamentais para seu bem-estar e tranquilidade, para tentar desenvolver uma maior consciência de seu próprio corpo, elevação de sua auto- 
estima e, portanto, melhores condições de prevenção das doenças sexualmente transmissíveis, gravidez indesejada e abuso sexual. (BRASIL, 1999). Portanto percebese que os educadores mencionados estão alicerçados neste importante aspecto, desfazendo idéias e conceitos errados expressos através da linguagem de forma simples e objetiva do ponto de vista científico.

b. Transposição didática: Tornar compreensível termos científicos, de acordo com a realidade e necessidade de cada faixa-etária. Observamos essa subcategoria nos participantes P1 e P5.

[...] e assim a gente nota que tem essa participação de ter uma abertura maior na linguagem para falar de orientação sexual, precisa falar a língua do público de hoje, do adolescente de hoje [...] (P5).

c. Contextualização do conteúdo: Trazer a realidade para mais perto, tentando mostrar num plano menos "abstrato" para os estudantes o que é discutido teoricamente, e que a maioria não tem conhecimento, propiciando maior atenção e interesse pela orientação. Identificamos essa categoria em P1 e P3.

[...] trago a realidade dos hospitais que eu vejo, lógico, é assim: não dizendo nome de paciente nem de hospital, mas de situação que você vê. Às vezes no hospital dá entrada uma criança de nove, dez anos para dar à luz [...] (P1).

d. Ajuda de outros profissionais: Ainda perdura, mais de uma década depois dos PCN serem publicados, a concepção de que os profissionais da área de saúde são os mais preparados para o desenvolvimento da orientação sexual. Isto sugere um desconhecimento do fato de que no currículo de profissionais da área de saúde não consta nenhuma disciplina de cunho específico sobre essa orientação (PAIVA, 1996). Segundo os PCN (BRASIL, 1999), o profissional responsável pela orientação tem como pré-requisito para a abordagem da temática, não necessariamente lecionar essa ou aquela disciplina ou pertencer à determinada área profissional, mas ter interesse e bom relacionamento com os educandos através de uma interlocução confiável, para acolher as expectativas, opiniões e dúvidas dos mesmos. No entanto, os professores precisam de ajuda, como pode ser observado em P2 e P3.

[...] perguntou eu paro, se eu souber, se eu não tiver entrosamento aí eu não falo digo que vou pesquisar, perguntar a um colega, às vezes para o médico $[\ldots](\mathrm{P} 2)$.

e. A abrangência da temática impossibilita a clareza da abordagem. A orientação 
sexual remete a inúmeras temáticas, que são de cunho social, psicológico, ético, histórico, antropológico, etc. Identificamos assim professores que por essas ou outras razões nem sempre conseguem ser claros. Enquadraram-se, nesta subcategoria, P2 e P6.

[...] eu acho que porque tem muitas coisas assim que aparecem de repente, que às vezes a gente não se sente preparado, às vezes um questionamento, às vezes uma colocação até dentro da sala mesmo, tem muitas coisas que aparecem que às vezes pega a gente de surpresa [...] (P6).

f. Não sabe a resposta, porém disponibiliza-se a pesquisar. Apenas P2 mostrou interesse em pesquisar, caso não saiba responder claramente aos estudantes.

[...] quando eu trabalho reprodução e sei que vão surgir algumas perguntas, eu deixo os alunos bem à vontade. Se perguntarem e eu souber eu digo, se não souber eu vou pesquisar. É assim a forma que eu trabalho (P2).

g. Questões sobre higienização: Para P3, sua clareza está relacionada ao link que a orientação pode ter com as questões de higiene, para tentar desmistificar alguns tabus.

[...] porque à medida que a gente vai dar uma orientação sexual a gente não deixa de falar na higiene onde muitas mães não orientam seus filhos nisso, tanto o homem como a mulher, não orientam, por exemplo: a menina tá menstruada aí não deve tomar banho, isso aí já peguei muito [...] tudo isso é falta de quê? De informação, entendeu? Então eu falo: é o período em que a menina tem que tomar mais banho, entendeu? Cabeça e tudo, que questão de subir pra cabeça isso não existe. São tabus que vêm muito das mães, botam muitas coisas na cabeça (P3).

\section{SISTEMATIZAÇÃO}

Em relação à sistematização, esta categoria desdobrou-se em três subcategorias, dentre as quais tivemos como subcategoria prevalente: independente do conteúdo aborda sempre a temática, contemplando quatro dos seis participantes, sendo a subcategoria analisada, interpretada e discutida, apesar de termos um consenso de que aspectos da sexualidade geralmente são trabalhados na abordagem dos sistemas reprodutores, pois estão diretamente articulados segundo a concepção da grande maioria dos educadores. Constatamos que apenas um, entre os seis participantes (P4), evidenciou essa subcategoria com a ressalva de que a temática é tão importante que precisa estar sendo "martelado" continuamente. Houve também a subcategoria: aborda quando acha necessário (P3), o que expressa total desarticulação com os PCN de orientação sexual, pois não deve ser por intermédio do "eu acho" que o educador deve orientar-se para o desenvolvimento de uma temática tão importante e de caráter transversal, o que lhe confere total relevância independente da disciplina ou até de conteúdos que 
estejam programados para serem desenvolvidos, o que segundo os PCN de orientação sexual em concordância com a Organização Mundial de Saúde, são claros "Se a saúde é um direito humano fundamental, a saúde sexual também deveria ser considerada como um direito humano básico." Como essas duas últimas subcategorias não foram prevalentes apenas discorremos sobre as falas que lhe conferiram tal classificação.

\begin{tabular}{|c|c|c|c|c|c|c|}
\hline Subcategorias & \multicolumn{6}{|c|}{$\begin{array}{l}\text { Distribuição das respostas dos } \\
\text { Professores }\end{array}$} \\
\hline a. Independente do conteúdo enfoca sempre a temática & $\mathrm{P} 1$ & $\mathrm{P} 2$ & & & P5 & P6 \\
\hline b. Aborda apenas quando o enfoque é sistema reprodutor & & & & $\mathrm{P} 4$ & & \\
\hline c. Aborda quando acha necessário & & & P3 & & & \\
\hline
\end{tabular}

Quadro 2 - Respostas dos professores em relação às subcategorias da categoria sistematização.

[...] já parei várias aulas, quando às vezes, estou trabalhando células, aí eu falo de células reprodutoras, e eles questionam muito. Aí, às vezes, aquela aula que eu comecei a trabalhar ela entra nesta parte, que eles ficam à vontade, fazem $\mathbf{N}$ perguntas, questão homossexual, questão bissexual. Um dia desse, o aluno perguntou: professora! Estava passando a novela, ele perguntou o que era transexual e eu tava dando matemática, aí eu parei a aula todinha de matemática e expliquei qual era a diferença entre trans, travesti, mas tudo isso porque tenho um livro que ganhei, eu também não sabia, aí eu busquei, comprei um livro e li, quando o menino perguntou eu sabia, se eu não soubesse eu tinha dito para ele: não sei nem a diferença kkkkk, mas como eu tinha lido, aí eu parei a aula e expliquei o que era transexual, o que é travesti, o que é hermafrodita, o que é homossexual, mas porque eu leio muito, aí expliquei, pronto, eu parei de dar a aula de matemática. Perguntou eu paro $[\ldots](\mathrm{P} 2)$.

Os professores expressam, através dos seus discursos, a disponibilidade contínua para abordar o tema, mesmo que para eles não tenha ligação alguma com o conteúdo abordado. Mostram interesse nas inquietações dos adolescentes e curiosidades em relação à sexualidade. Percebe-se através de suas falas que o objetivo principal dos PCN, está sendo contemplado, pois o documento foi desenvolvido com a finalidade de sistematizar a ação pedagógica da escola em relação às questões da sexualidade, bem como estabelecer que a satisfação da curiosidade entre os estudantes contribua para que o desejo de saber seja estimulado, não só a curto prazo, porém: "ao longo da vida." A não satisfação dessa curiosidade, geraria ansiedade, tensão e, possivelmente a inibição da capacidade investigativa. É justamente esta disponibilidade para a abordagem no esclarecimento das dúvidas, que promoverá o incentivo para que os educandos continuem formulando novas questões, contribuindo assim, para o alívio das ansiedades, que muitas vezes interferem no aprendizado, como um todo, dos conteúdos escolares. Consideramos relevante darmos abertura para o que argumentam os PCN, em 
relação ao trabalho sistemático da orientação sexual.

O trabalho sistemático de Orientação Sexual dentro da escola articula-se, também, com a promoção da saúde das crianças, dos adolescentes e dos jovens. A existência desse trabalho possibilita a realização de ações preventivas das doenças sexualmente transmissíveis/Aids de forma mais eficaz. Diversos estudos já demonstraram os parcos resultados obtidos por trabalhos esporádicos sobre esse assunto. Inúmeras pesquisas apontam também que apenas a informação não é suficiente para favorecer a adoção de comportamentos preventivos. Reconhecem-se, portanto, como intervenções mais eficazes na prevenção da Aids, as ações educativas continuadas, que oferecem possibilidades de elaboração das informações recebidas e de discussão dos obstáculos emocionais e culturais que impedem a adoção de condutas preventivas [...] (BRASIL 1999 p. 293).

As falas abaixo são dos professores P3 e P4:

Tema, olhe esse ano não, mas já trabalhei, aí depende da necessidade dos alunos, eu dou oficina de educação sexual (P3).

[...] $\mathrm{Na}$ sexta série agora estou trabalhando sobre vírus, baseando a AIDS como foco, então a gente trabalhou bastante eu estabeleci perguntas pra eles, senti a dificuldade do alunado em entender quais são os mecanismos de transmissão da AIDS então a gente trabalhou em relação a AIDS [...] (P4).

\section{ATITUDES DE ACOLHIMENTO ÀS EXPRESSÕES DOS ADOLESCENTES}

Em relação às subcategorias da categoria atitudes de acolhimento, identificamos respectivamente: receptividade e quebra de tabus, as quais analisamos, interpretamos e discutimos segundo os PCN. Mencionamos a seguir, as falas dos participantes que foram alocadas nas quatro subcategorias: acessibilidade, respeito aos pares, respeito às diferenças e imparcialidade.

\begin{tabular}{|l|l|l|l|l|l|l|}
\hline \multicolumn{1}{|c|}{ Subcategorias } & \multicolumn{5}{c|}{ Distribuição das respostas dos } \\
professores \\
\hline a. Receptividade & P1 & P2 & P3 & & & P6 \\
\hline b. Quebra de tabus & P1 & & P3 & & P5 & \\
\hline c. Acessibilidade & P1 & P2 & & & & \\
\hline d. Respeito aos pares & P1 & & & P4 & & \\
\hline e. Respeito às diferenças & P1 & & & P4 & & \\
\hline f. Imparcialidade & & P2 & P3 & & & \\
\hline
\end{tabular}

Quadro 3 - Respostas dos professores em relação às subcategorias da categoria atitudes de acolhimento às expressões dos adolescentes.

a. Receptividade: P1, P2, P3, e P6, em seus relatos disseram, em exemplos ou 
declarações, que estavam sempre receptivos às expressões dos estudantes, não tendo indiferença quanto as suas expectativas.

[...] Eu não entendi esse negócio professora, estou em dúvida! Dá para conversar com a senhora? Me chamam no corredor então eu abro, o que eles perguntarem eu respondo, então não tem esse negócio porque a pergunta é feia não, a pergunta foi essa a resposta é essa [...] (P1).

[...] às vezes tem professor que não consegue conversar com o aluno inclusive aí, no ano passado uma aluna que estudava numa escola de grande porte, teve uma professora que colocou ela pra fora e ela disse a mim quando o menino perguntou no linguajar dele, eu nem me lembro da pergunta, eu levei tudo na brincadeira, eu disse: "não minha gente, são os apelidos que vocês estão aprendendo." Professora na minha escola, eu vim da escola particular, quando eu perguntei sobre isso a minha professora me botou pra fora, mas uma orientação sexual não existe dessa forma [...] e às vezes tem professores que não gostam de falar sobre esse assunto, algumas perguntas que vão fazer [...] Eu não! Eu levo tudo nas costas [...] (P2).

Quanto à receptividade demonstrada pelos professores, os mesmos relatam exemplos vivenciados ou suas ações frente a alguma situação, que exigiu deles: atenção disponibilizada ao educando, em relação a alguma dúvida; curiosidade e desejo de falar sobre o tema, independente se dentro ou fora da sala de aula. Disseram estar receptivos a qualquer diálogo sem distinção, pois não há pergunta considerada imprópria, nem momentos inadequados. A atitude objetivou dar abertura para propiciar a conversa, a explicação ou o esclarecimento, sem defensivas. Os educadores, aplicam em suas práticas o que lhes compete, que é justamente identificar as manifestações dos estudantes, como as curiosidades acerca dos aspectos da sexualidade e intervir pontualmente, permitindo que as dúvidas possam ser colocadas e o assunto trabalhado. Essa intervenção deve esclarecer as dúvidas dos estudantes e, se o tema for de interesse geral, o professor deve oferecer espaço para discussão e esclarecimento. Essa criação desse espaço pode ajudar o jovem a passar por essa fase com menos angústia. (BRASIL 1999).

b. Quebra de tabus: P1, P3 e P5, disseram em seus relatos que tinham como um dos focos nas abordagens da temática a quebra de tabus, para melhor acolher as expressões dos adolescentes:

[...] então eles não têm tabu comigo, eu não recrimino nada, não condeno, eu não critico, porque quem sou eu para criticar alguma coisa dos meus alunos? Eu só procuro orientar da melhor forma, porque eles não têm orientação dos pais, de irmãos mais velhos, eles são soltos [...] (P1). 
Falando sobre o câncer de pênis em Pernambuco, mencionando que ocupa o $2^{\circ}$ lugar em amputações no país, P5 orientou:

[...] É séria a questão do não lavar corretamente, de não usar o preservativo, é, acho que na verdade existe uma ignorância generalizada sobre o tema, porque tudo é muito tabu ainda, então parte do princípio que você não pode ter tabu pra falar de orientação sexual, aí você consegue, de fato, orientá-lo sexualmente a partir do momento que ele tiver o conhecimento, ele pode fazer as escolhas corretas. È por aí! (P5).

Os educadores afirmam que em sua prática em relação à orientação sexual, não aceitam tabus, mesmos os estudantes estando inseridos num contexto familiar e/ou social que incentive a perpetuação dos tabus. Eles trabalham essa questão com transparência, sem julgamento ou imposição, mas prestando os esclarecimentos necessários para que os estudantes possam ter acesso aos aspectos importantes da temática, e, consequentemente, possam fazer suas escolhas e ter suas próprias concepções sobre o tema. Os PCN, por sua vez, incumbem a escola exatamente de informar, problematizar e debater os diferentes tabus, preconceitos, crenças e atitudes existentes na sociedade, buscando por sua vez não a isenção total, o que seria impossível, mas que os educadores mantenham um distanciamento das opiniões e aspectos de âmbito pessoal entre os mesmos para poder desempenhar essa tarefa.

c. Acessibilidade: P1 e P2 disseram que os estudantes tinham livre acesso aos mesmos, não importando se em sala ou fora da sala de aula, tendo por sua vez suas expressões acolhidas:

[...] eles têm em mim mais que uma professora, de orientação sexual. Eles têm em mim uma amiga, então eles perguntam sobre sexo anal, vaginal; fazem exame e vêm trazer para eu dar uma olhadinha, porque eu faço enfermagem. Eles têm em mim um ponto de apoio, pois com os demais professores fica um pouco mais difícil, então eles têm muito acesso a mim a tudo, qualquer coisa eles jogam no meu e-mail a pergunta e eu dou a resposta (P1).

d. Respeito aos pares: P1 e P4 declararam em suas entrevistas, a ênfase dada à questão do respeito entre os próprios estudantes e que era trabalhado pelos mesmos, buscando conscientizá-los sobre a necessidade de respeito ao próximo.

[...] eu acho que orientação sexual é o sentir, é a busca do prazer, da vontade, daquela maneira que ele acha correto ou não é correto, certo! É a maneira que eles sentem prazer, então eu acho a orientação sexual, muito importante é um tema discutido, porque pode ajudar a conscientizar aos outros a respeito do sentimento ao próximo do respeito ao semelhante é um tema importante porque pode facilitar o homem em si, ajudar o seu semelhante, a respeitá-lo, 
respeito ao próximo então é importante a orientação sexual com certeza (P4).

f. Respeito às diferenças: P1 e $\mathbf{P 4}$ enfocaram a pertinência de uma orientação que leve em consideração os preconceitos, que precisam ser mais trabalhados nessa faixa etária, objetivando melhor esclarecimento e conscientização quanto às diferenças.

[...] Na orientação sexual a gente fala um pouquinho sobre como a sociedade recrimina tanto o homossexual como também o portador de HIV, a gente vê paralelo isso, aí também a gente fala em métodos anticonceptivos, falamos sobre respeito às diferenças como é um tema transdisciplinar, todas as diferenças e cai em cima do homossexualismo porque a gente tem um público aqui que tem jovens que se consideram, já têm aparência super pop, já gritam como homossexuais, então a gente liga todos os fatores [...] é orientação sexual, prevenção, mecanismo de transmissão [...] (P4).

g. Imparcialidade: $\mathbf{P 2}$ e P3, disseram ser imparciais nas suas abordagens, para evitar um maior distanciamento das opiniões e aspectos pessoais dos mesmos, em concordância com o que é pretendido pelos PCN. Na relação educador e educando a percepção do estudante é preterida, o professor constitui-se numa referência muito importante para o educando. A emissão de opinião pessoal do professor na sala de aula pode ocupar o espaço dos questionamentos e incertezas, que segundo os Parâmetros Curriculares são necessários para a formação da opinião do próprio estudante. Os adolescentes testam, questionam e tomam como referência a percepção que têm da sexualidade de seus professores, em busca de seus próprios parâmetros (BRASIL, 1999).

[...] educação sexual é uma coisa que você tem que ter muito cuidado quando você for dar essa orientação, por exemplo: O homossexual você não pode chegar assim diretamente e falar homossexual, se você concorda ou não concorda, você não pode falar isso de maneira nenhuma, então por exemplo chegou uma aluna para mim aí perguntou assim: "professora qual é a idade certa de se engravidar?" Aí eu disse a ela: "A idade certa é a tua responsabilidade que vai dizer, se você está preparada para ser mãe para engravidar então, a hora quem vai dizer é você" [...] (P3).

\section{DOMÍNIO DO CONTEÚDO A SER ENSINADO}

Na categoria domínio de conteúdo a ser ensinado, observamos que não houve nenhuma subcategoria prevalente, mas, por sua vez, houve uma distribuição entre as respostas dos educadores, onde evidenciamos uma espécie de equidade quanto a essa categoria, pois em todas as subcategorias enquadraram-se três educadores, ou seja, metade dos participantes. Segundo a perspectiva adotada nas demais categorias, não havendo 
nenhum aspecto prevalente, faremos apenas uma sucinta análise da subcategoria (c) preparação, sendo as demais subcategorias citadas com os respectivos discursos dos docentes.

\begin{tabular}{|c|c|c|c|c|}
\hline Subcategorias & \multicolumn{4}{|c|}{$\begin{array}{l}\text { Distribuição das respostas } \\
\text { dos professores }\end{array}$} \\
\hline a. Correção dos conceitos & $\mathrm{P} 1$ & $\mathrm{P} 2$ & P3 & \\
\hline b.Conhecimento dos termos empregados & $\mathrm{P} 1$ & $\mathrm{P} 2$ & P3 & \\
\hline c. Preparação & $\mathrm{P} 1$ & & P3 & P5 \\
\hline d. Utilização de materiais didáticos & P1 & $\mathrm{P} 2$ & & P5 \\
\hline
\end{tabular}

Quadro 4 - Respostas dos professores em relação às subcategoria da categoria domínio do conteúdo a ser ensinado.

a. Correção dos conceitos: P1, P2 e P3 disseram, em suas entrevistas, que corrigem conceitos errôneos, que muitas vezes são os conhecimentos prévios dos estudantes, mas que precisam ser corrigidos e melhor definidos.

[...] Porque se um aluno chegar para você como a gente pegava muito com aquelas palavras bem vulgar tipo: rôla, tabaco,... nisso aí você aproveita se um aluno chegar para dizer essa rôla, eu escrevo no quadro e dou a aula de educação sexual entendeu? [...] (P3).

b. Conhecimento dos termos empregados: os mesmos professores, P1, P2 e P3, declararam que tinham pleno conhecimento dos termos que usavam para as aulas de orientação sexual.

[...] eu parei a aula e expliquei o que era transexual, o que é travesti o que é hermafrodita o que é homossexual, mas porque eu leio muito aí expliquei pronto, eu parei de dar a aula: perguntou eu paro [...] (P2).

c. Preparação: Não foram enquadrados nesta categoria os professores que disseram de forma direta ou indireta, que não se sentiam seguros para responder aos questionamentos dos estudantes: P2, P4 e P6. Os demais participantes disseram ter preparação em vários aspectos. Vejam o que diz o professor que se considera despreparado:

[...] Acho que nunca ninguém está preparado, requer aprofundamento, estudo, porque qualquer projeto vai ter um foco em relação à orientação sexual $[\ldots](\mathrm{P} 4)$. 
Metade dos professores consideram-se despreparados para a abordagem do tema, tendo como argumento diversas situações peculiares, ou mesmo as suas limitações sendo explicitadas frente aos interesses dos estudantes. Observamos o mesmo número de professores considerando-se preparados (P1, P3 e P5), porque já atuam na área há vários anos, participam ou participaram de vários cursos e/ou formação continuada que lhes conferiram esse embasamento. O fato de terem outra formação paralela na área de saúde (mencionado por P1 e P5) os fundamenta para inúmeras situações que acreditam não serem dominadas por outro professor restrito à atuação pedagógica. Os PCN, em relação ao aspecto preparação descrevem o que definem como preparação para a abordagem, que seria possibilitar a construção de uma postura profissional e consciente na abordagem do tema. Os educadores necessitam entrar em contato com suas próprias dificuldades diante do assunto, através de questões teóricas, leituras e discussões referentes à sexualidade e suas diferentes abordagens, preparando-se assim, para, uma intervenção prática junto aos estudantes. Uma formação continuada sistemática que propicie a reflexão sobre valores e preconceitos dos próprios educadores, para que reconheçam os valores que regem seus próprios comportamentos e orientam sua visão de mundo, é que possibilitará condições favoráveis para o esclarecimento, a informação e o debate.

d. Utilização de materiais didáticos: Enquadramos nesta categoria os professores que disseram abordar a orientação sexual, com auxílio de recursos didáticos, como fotos, atlas, transparências, etc. (P1, P2 e P5).

[...] eu costumo utilizar modelos anatômicos, costumo utilizar cartazes, atlas, é pra ter uma questão bem impactante, a gente usa muito atlas, para que eles possam ver o que pode acontecer se eles não tiverem uma educação sexual legal $[\ldots](\mathrm{P} 5)$.

\section{ASPECTOS TRANSDISCIPLINARES}

No quadro 5 temos as subcategorias da categoria aspectos transdisciplinares. A subcategoria prevalente foi: não possui aspectos transdisciplinares e nela estão enquadrados cinco dos seis professores. Analisamos os resultados assim como interpretamos e discutimos esses dados, intercalando comentários, observações pertinentes sobre alguma afirmativa e explicitamos as falas dos professores que 


\section{justificam essa classificação. Quanto à subcategoria possui aspectos}

transdisciplinares, apenas o professor (P1) enquadrou-se. Tecemos, neste caso, apenas um breve comentário sobre os dados e apresentamos a respectiva fala do docente confirmando essa classificação.

\begin{tabular}{|c|c|c|c|c|c|c|}
\hline Subcategoria & \multicolumn{6}{|c|}{$\begin{array}{l}\text { Distribuição das respostas dos } \\
\text { professores }\end{array}$} \\
\hline a. Não possui aspectos transdisciplinares & & $\mathrm{P} 2$ & P3 & $\mathrm{P} 4$ & P5 & P6 \\
\hline b. Possui aspectos transdisciplinares & P1 & & & & & \\
\hline
\end{tabular}

Quadro 5 - Respostas dos professores em relação às subcategorias da categoria aspectos transdisciplinares.

a. Não possui aspectos transdisciplinares: Cinco dos seis professores disseram não possuir um cunho transdisciplinar em suas abordagens. A maioria deles aponta para uma evidente necessidade dessa característica, para o desenvolvimento de uma orientação formativa e não apenas informativa. No entanto, são necessárias políticas públicas de estruturação administrativa e de formação que contemplem os docentes, fundamentado-os para tal objetivo.

[...] Olha esses trans, essas palavras aí, eu já fiz até um curso também pela prefeitura, alguma coisa a gente entende, que tudo isso aí: trans, multidisciplinaridade, que mais, interdisciplinaridade é muito difícil na prática, isso é muito bonito, já vi, já fiz curso, mas na prática é muito difícil porque a gente tem um sistema: aquela forma didática das aulas então você vê dez minutos é o que a gente tem, quer dizer vinte minutos de lanche, a gente às vezes nem tem tempo de conversar com um colega sobre a disciplina, às vezes, é tudo assim: aula, aula, aula e tudo em cima de aula, aula, então esses termos que se usa trans, multi, inter, é meio vago, aí quando chega na prática eu não sei se a gente já faz inconscientemente, ou a gente não faz nada, as aulas continuam assim do mesmo jeito que era como duzentos anos atrás, aquele sistema: o professor com a carga horária muito grande sem tempo para sentar, eu uma vez até fazia a interdisciplinaridade inclusive com matemática eu fazia algumas perguntas assim, quando chegava uma época dessas fazia algumas perguntas eu mesmo elaborava, porque o professor é criativo, mas depois isso vai por água abaixo, porque o Estado faz muito tempo que eles não oferecem nenhuma capacitação nessa parte de orientação, nessa parte de trans, multi, inter. Eu fiz várias, se você perguntar a mim o que é? Eu não sei não, porque a gente entra na escola é para dar aula e trabalhar os conteúdos previstos, aqueles que há possibilidade de fazer porque às vezes o conteúdo é extenso, mas às vezes o alunado não acompanha, eu, pelo menos uma coisa que aprendi nessa minha carreira, que eu só faço o possível, o ideal, eu nem mais me preocupo, mas eu faço o possível dentro das minhas limitações, das condições do trabalho, aí mais do que isso eu não me iludo mais, porque é muito difícil, eu acho que para 
existir tudo isso, deveria na minha experiência que tenho, era começar com a carga horária. Uma carga horária muito grande que a gente tem, é só aula só aula, aula, a gente não tem assim um período um tempo para se sentar fazer tudo isso, conversar com o professor, trabalhar. Porque hoje o ensino é fragmentado o que eles querem é uma integração, mas, é muito difícil esta integração no ritmo que se faz aí [...] (P2).

Percebe-se que P3, além de não saber que a orientação sexual é uma temática transdisciplinar, desconhece qual o objetivo de uma prática transdisciplinar. P2, P4, P5 e P6 mostraram ter algum nível de conhecimento sobre as características transdisciplinares do tema orientação sexual, entretanto, não dizem que aplicam em sua prática pedagógica. Ao invés disso remetem a responsabilidade às instâncias políticas, que se omitem na orientação aos professores de todas as disciplinas em relação a esse trabalho. Alguns reconhecem que a temática é complexa e não pode ser trabalhada de forma fragmentada, por um único professor, ou esporadicamente, através de alguma palestra ministrada por algum "especialista" de áreas co-relacionadas. Fortes argumentos são dados como justificativa, como o fato apontado por P2, questionando esse sistema que perdura há séculos; sobre o número de aulas excessivas para o professor, inviabilizando seu contato com os demais colegas de trabalho e sobre o tempo disponibilizado com poucos minutos de intervalo. Ainda é enfática ao assumir não ter ilusões quanto a mudanças. Os professores estão apresentando-se, neste aspecto, desarticulados das propostas do PCN de orientação sexual, pois o documento foi elaborado optando-se por integrá-lo através da transversalidade, o que significa que tanto as concepções quanto os objetivos e conteúdos propostos, encontram-se contemplados pelas diversas áreas do conhecimento, como forma de alcançá-la na sua complexidade. Por envolver problemáticas sociais atuais e urgentes, consideradas de abrangência nacional e até mesmo de caráter universal, nos dias de hoje, a transversalidade pressupõe um tratamento integrado das áreas e um compromisso das relações interpessoais e sociais escolares com as questões que estão envolvidas nos temas, a fim de que haja uma coerência entre os valores experimentados na vivência que a escola propicia aos alunos e o contato intelectual com tais valores:

Assim, os objetivos se definem nos PCN em termos de capacidades de ordem cognitiva, física, afetiva, de relação interpessoal e inserção social, ética e estética, apontando, desta forma, uma formação ampla. A explicitação de metas no processo educativo em termos de capacidades torna presentes diferentes aspectos do desenvolvimento humano que fazem parte da educação escolar, redimensionando a excessiva fixação no desenvolvimento de capacidades cognitivas, tão comum nos currículos escolares (BRASIL, 
1997 p. 51).

b. Possui aspectos transdisciplinares: apenas P1 diz que contempla alguns aspectos da transdisciplinaridade. Não mantém sua abordagem apenas no cunho disciplinar, conteudista. Entretanto, essa característica não foi observada apenas no desenvolvimento da orientação sexual, mas, em sua prática no ensino da biologia como um todo.

[...] Pelo que eu entendo da transdisciplinaridade, é uma disciplina que está agregada à outra. É assim no caso como eu procuro trabalhar com os meninos, começa um assunto então puxo um pouco de história, aí vem a parte de química, aí também puxo química para não trabalhar os meninos como que as informações fossem engavetadas: então essa aqui é história, está dentro desta gaveta; matemática, e eles aprendem a engavetar eles não aprendem a ver as disciplinas como um todo. Ligar uma disciplina à outra, isso é uma dificuldade imensa. Primeiro porque vejo que eles não sabem ler, ler não é ver os símbolos, é entender! Eles não entendem o que eles estão lendo, não sabem interpretar um texto, e imagine fazer a união das disciplinas e até porque muitos professores dizem: "é minha disciplina! Então se fecham nisso não procuram abrir né? Fazer uma ligação com outras disciplinas, eles não fazem, aí pedem: "professora, a senhora tira uma dúvida de química? Tira uma dúvida de história, uma dúvida de geografia, de literatura? Mas todo mundo tem obrigação quando é professor de tá se informando, não é porque sou uma professora de biologia que eu não vá conhecer autores de língua portuguesa, que eu não vá gostar de um escritor. Isso é problema, minha disciplina é essa então só trabalho isso, não tem a união delas. As disciplinas são dadas por gaveta, por assunto e coloca nos pés dos meninos todas engavetadas. Aí quando pegam uma professora como eu, eles estilam, porque eu saio puxando toda a informação se é uma palavra, que sufixo é esse? Qual a origem dessa palavra? O que isso quer dizer? Eles ficam assim: Mas professora, isso é português? É fui corrigir os trabalhos, nota baixa, porque eu fui ver acentuação gráfica, pontuação, divisão de sílaba que eles não sabem fazer no $2^{\circ}$ ano médio, quer dizer, se todo professor corresse atrás e batesse, a gente se unisse para formar realmente esses meninos com uma visão ampla crítica a gente teria um resultado melhor [...] (P1).

\section{CONSIDERAÇÕES FINAIS}

Salientamos que não houve a pretensão de traçar uma investigação de cunho avaliativo da abordagem dos docentes quanto a essa temática. Evidenciamos o explícito desconhecimento por parte dos educadores das recomendações dos PCN, para a abordagem da orientação sexual. Os mesmos afirmavam de várias maneiras que o documento, não faz parte da sua prática-pedagógica. Outros se referem aos Parâmetros Curriculares como documento sem objetividade e clareza, que não desperta o interesse do educador, que poderia fazer parte da realidade docente se houvessem políticas de apoio ao educador, principalmente na esfera da formação continuada. Houve até quem dissesse ter lido alguns temas dos PCN apenas para concursos. 
Um dos fatos mais gritantes foi a constatação do desconhecimento por professores da orientação sexual como um tema transversal nos PCN. Todos os professores, por sua vez disseram conhecer os PCN, alguns trabalharam com o documento em cursos de especialização, mas todos afirmaram ter recebido nas escolas em que lecionavam exemplares de sua área específica de conhecimento além dos temas transversais. Via de regra, não existe nenhuma base nos PCN, para a abordagem da orientação sexual na prática dos professores no estudo desenvolvido, pois os professores em seus relatos deixaram explícito o desconhecimento dos aspectos pontuados como importantes para a abordagem da temática. Contudo constatamos nos resultados uma espécie de atuação tácita dos professores, que de alguma forma apresentavam características dos PCN importantes para a abordagem, como subentendida pelos próprios professores.

Em alguns, essas características identificadas para a abordagem da orientação sexual, possivelmente são fundamentadas em trabalhos do qual esses educadores fizeram parte, como cursos de educação sexual, leituras diversas, especialização, etc. Algumas dessas características foram: sistematização e atitudes de acolhimento, imparcialidade. Contudo percebe-se que a atuação transdisciplinar ainda não permeia a prática dos professores quanto à orientação sexual, divergindo totalmente da proposta do documento supracitado. Concluímos por sua vez que as categorias clareza e domínio do conteúdo, não foram enquadradas como convergente ou divergente por não apresentarem subcategoria prevalente, pois no máximo metade dos participantes foi alocados em ambos os casos, portanto foi necessário considerarmos este fato para inferir os resultados, ressaltando o número de participantes.

\section{REFERÊNCIAS}

BRASIL, Parâmetros Curriculares Nacionais/ Ensino Fundamental: Orientação sexual. Brasília: Ministério da Educação, 1999.

OLIVEIRA, B. M. Sexualidade na escola: Um estudo sobre as representações dos docentes do ensino fundamental. (Dissertação de mestrado). UFPE, 2001.

OLIVEIRA, M.M. Como fazer pesquisa qualitativa. Recife: Bagaço, 2005.

PAIVA, V. Sexualidades adolescentes: escolaridade, gênero e sujeito sexual. In: PARKER, R.; BARBOSA, M. (Orgs) Sexualidades brasileiras. Rio de Janeiro: Relume Dumará: ABIAS/MS/UERJ, 1996. 